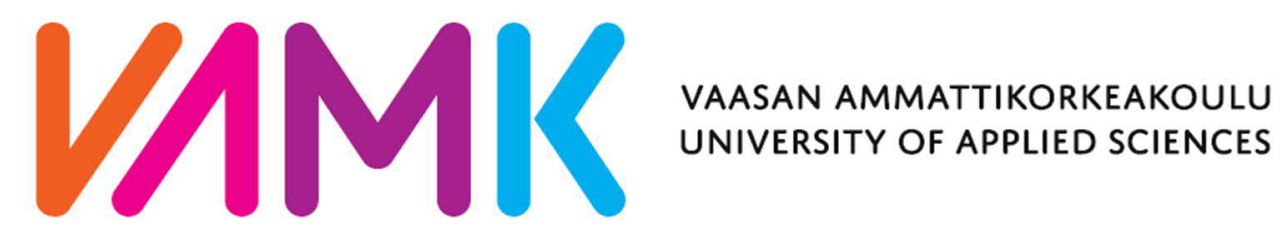

THIS IS AN ELECTRONIC REPRINT OF THE ORIGINAL ARTICLE

Please cite the original article:

Nurhayati, Marhayani, D.A., Chang, CH. \& Naaranoja, M. 2019. Math Anxiety Analysis in Indonesian Elementary School. In: Uden L., Liberona D., Sanchez G., Rodríguez-González S. (Eds.) Learning Technology for Education Challenges. LTEC 2019. Communications in Computer and Information Science, vol 1011. Springer, Cham, 292-301.

https://doi.org/10.1007/978-3-030-20798-4 25

Version: Final draft

Copyright: @ 2019, Springer Nature Switzerland AG 


\title{
Math Anxiety Analysis in Indonesian Elementary School
}

\author{
Nurhayati $^{1}$, Dina Anika Marhayani ${ }^{1}$, Chih-Hung Chang $^{2}$, Marja Naaranoja ${ }^{3}$ \\ ${ }^{1}$ STKIP Singkawang, Singkawang 79251, Indonesia \\ ${ }^{2}$ National University of Kaohsiung, Kaohsiung, Taiwan \\ ${ }^{3}$ Vaasa University of Applied Sciences, Finland \\ nurhayati@stkipsingkawang.ac.id
}

\begin{abstract}
The starting point of the research was the fact that the math results in the region were low according to the international evaluation. The paper also aims to make new math anxiety questionnaire since the existing math anxiety inquiries focus mainly on feelings of learners and we wanted to study psychological, physiological and social elements of math anxiety using the viewpoints of Dacey and Fiore (2000). This questionnaire is compared to existing ones and the comparison shows that the questionnaire has new viewpoints. The results show that the anxiety level of the 1-6 graders was mostly low. The developed math anxiety tool needs further development.
\end{abstract}

Keywords: math anxiety, learning mathematics, math anxiety questionnaire, elementary school

\section{$1 \quad$ Introduction}

This study assesses whether elementary school 1-6 graders (7-13 year old children) in primary school 03 Sajingan Besar have math anxiety. The school is near to the Indonesia-Malaysia border where the mathematical ability of students has been assessed to be low (Syachrumsyah, 2017). We want to understand whether the poor math skill results (Mullis, et al, 2008; Mullis, et al, 2012) are outcomes of math anxiety that starts already in elementary school. One of the interesting viewpoints is that Sukmadinata (2004) revealed that anxiety and worry also have a positive value, as long as the intensity of the anxiety is not too strong, because high, medium, and light anxiety can be a motivation. We need to be aware that the math anxiety is not always bad.

The other reason for this study is is to create math anxiety questionnaire by using Dacey and Fiore (2000) reasoning that anxiety has psychological, physiological and social elements. The focus of the earlier anxiety questionnaires is mainly a bit narrower since they focus on feelings of the learners. We aim to compare the created anxiety questionnaire with the existing math anxiety questionnaires. 
Learning mathematics requires abstract, axiomatic and deductive skills (Hamzah \& Squares, 2009). However, abstract thinking of children in elementary school is still evolving. Because of this, elementary school teachers are forced to connect pupils understanding from the concrete to abstract.

According to Ramirex et al (2013) a self-report measure of math anxiety is associated with math achievement in children as early as first and second grade. According to them math anxiety measure is not related to children's reading achievement, suggesting it is not just a proxy for general academic anxiety.

\section{Math Anxiety}

\subsection{Math anxiety and its results}

According to Mohd et al (2013) the math anxiety is due to the past life experience; social force and family expectations; negative attitudes and thoughts towards mathematics; method of teaching; influence of peers; situation and instrumentality of test or examination; poor curriculum; repressed emotions and physical causes and also myths related to mathematics, for example believing that mathematical skills are born naturally or there is a magic key to solve mathematic problem or girls don't learn mathematics.

Math anxiety can be a real fear, the root of which can be affective and cognitive, with people's belief influencing the way they think about mathematics and subsequently affect their learning (Jackson, 2008: 41). Math anxiety may cause children to fear mathematics. The anxiety may hinder a child's ability to make math a relevant part of their everyday life (Rossnan, 2006: 1).

Working memory is linked to math anxiety. The more working memory capacity one has, the better the performance on academic tasks such as problem solving and reasoning (Engle, 2002) and the better they are at regulating their emotional experiences (Schmeichel \& Demaree, 2010; Schmeichel, Volokhov, \& Demaree, 2008). However when they are in a stressful situation when the working memory capacity cannot be used normally their results are more poor. But a person who has low working memory has learned to use the reasoning and other strategies than memorizing. This explains that when a low working memory people are in stressful situation they still rely on the other skills than memorising they will perform better than a person who normally can rely on working memory. (Ramirez et al 2013)

Willis (2010) claims that elementary level pupils with math anxiety do not develop higher-order thinking skills. Higher-order thinking comprises creative problem solving and emotional response control that are needed to solve math problems and manage complex technology (Willis, 2010). 


\subsection{Math anxiety questionnaires for elementary level pupils}

There are not many researchers who have examined math anxiety of young children. There are three main scales available to assess math anxiety of pupils in elementary school. The 22-item Mathematics Anxiety Scale for Children (MASC; Chiu \& Henry, 1990) is based on the MARS (that was aimed for older students) but shortened for use with children in upper elementary grades. The MASC uses a 4-point Likert-type scale and has good evidence based on internal structure $(\alpha=.92)$ and strong evidence based on relations to other variables (i.e., test anxiety and school achievement motivation). The Mathematics Anxiety Survey (MAXS; Gierl \& Bisanz, 1995) is a 14-item assessment using a 5-point Likert-type scale also based on the MARS but included pictoral depictions of anxiety to clarify the response options for children. The MAXS also has good evidence based on internal structure $(\alpha=.85$ for third grade and $\alpha=.87$ for sixth grade) and strong evidence based on relations to other variables (i.e., test anxiety and math attitudes). Finally, the 26-item Suinn Mathematics Anxiety Rating Scale, Elementary Form (MARS-E; Suinn, Taylor, \& Edwards, 1988) uses a 5-point Likert-type scale and also has good evidence based on internal structure $(\alpha=.88)$ and strong evidence based on relations to other variables (i.e., standardized math subtest scores). Ramirez et al 2013 and Jameson 2013 created their own math anxiety questionnaire for elementary school children using the above mentioned questionnaires. Both of them focused on psychometric measures like the earlier math anxiety questionnaires.

Jameson (2013) created a pool of 20 items based on academic content standards for elementary math. The pool of items was revised by five experts who suggested minor rewording and independently confirmed the items' appropriateness. A pilot test of the 20-item Children's Anxiety in Math Scale (CAMS) revealed that four items were not functioning similarly to one another or to the other items on the scale. Those four items were removed, leaving the current 16-item scale. The questionnaire expresses 16 issues like "When solving math problems I feel " and "When teacher calls me to answer math question I feel".

Ramirez (et al 2013) made questions that evaluated the math anxiety attitudes of 1-2 graders in elementary school. Children were asked what they felt when solving a particular problems that were drawn from mathematics-teaching workbooks for children in the early elementary grades (e.g., "There are 13 ducks in the water, there are 6 ducks on land, how many ducks are there in all?''). Other items asked children about specific situations they might be confronted with at school concerning math (e.g., "being called on by a teacher to explain a math problem on the board"'). They asked children to make their responses about each question using a sliding scale that featured a calm face on the far right, a semi nervous face in the middle, and an obviously nervous face on the far left. The researchers encouraged all children to use the full continuum of the scale. The questionnaire highlighted that already in early elementary school level children faced math anxiety that potentially effected on math achievement. (Ramirez et al 2013) 
In addition, it is possible to evaluate the anxiety level by someone who is trained to see physiological signs of anxiety and the actions associated with them. Psychiatrists and psychologists are the experts who are trained to diagnose such a problem and can give a third party opinion. This is seen as a must issue when the anxiety is serious. (Shishigu 2018)

\subsection{How to reduce math anxiety}

The researchers have found following methods that either prevent or minimize the effect of math anxiety

1. Parents learn to believe that their children have enough good mathematics abilities, to express normal expectations, and avoid comparing the mathematics abilities or achievement of one child with that of another (Mohd et al 2013).

2. Psychological Techniques like anxiety management, desensitization, counseling, support groups, bibliotherapy, and discussions.

3. Once a student feels less fearful about math, he/she may build their confidence by taking more mathematics classes.

4. Most research shows that until a person with math anxiety has confronted this anxiety by some form of discussion/counseling no "best practices" in math will help to overcome this fear (Furner, 2007).

5. The teachers should emphasize problem solving in mathematics learning and practicing cooperative learning in small groups ( $\mathrm{Ma}$ and $\mathrm{Xu}, 2004$ ). Make the learning fun since students who consider mathematics as enjoyable usually show good performance (Deci and Ryan, 2002). Take into consideration the ability to think in abstract level. Relate math to real life as often as possible. Encourage critical thinking, engaged in exploring, thinking, practicing, and using knowledge, rather than listening to verbal descriptions of concepts. This can be done for example by games (e.g. Geist, 2010). Practice math problems daily since this supports the confidence development needed to solve mathematical problems (e.g. Freedman, 2010). There are also tools that help to teach math like Geogebra (Furner and Marinas 2012)

\section{$3 \quad$ Method}

\subsection{Research Approach and Strategy}

The research is qualitative and quantitative research. The pupils assessment of their experienced math anxiety is verified by asking the teachers opinion of the observed math anxiety.

The qualitative part is the part how we created the questionnaire.

The actual analysis of the answers when using the questionnaire was quantitave. 


\subsection{Research aim}

The aim of this study is to create a math anxiety questionnaire that studies feelings, physiological symptoms, and social elements of math anxiety. The aim is also to use the questionnaire in order to find out what are the 1-6 graders math anxiety levels in elementary school 03 Sajingan Besar.

\subsection{Developing the questionnaire}

Questionnaire was developed based on the interviews of children and teachers. Math anxiety questionnaire divides different angles of anxiety.

Data reduction aimed to simplify and transform the raw data that was got when interviewing the pupils at shcool. Data was first summared, encoded, themes were searched, groups made, memos writen and finally the aim was take away (reduce) the data/information that is not relevant

The following table describes the statements that were formulated based on the interviews and the expert finally validated statements and formulated them as is seen in the Table 1:

Table 1. Statement Before and After Validation

\begin{tabular}{|c|c|c|}
\hline No. & Statement Before Validation & Statement After Validation \\
\hline 1 & $\begin{array}{l}\text { Fear to get it wrong when completing } \\
\text { math assignments. }\end{array}$ & $\begin{array}{l}\text { I am afraid to get a wrong answer when } \\
\text { completing math assignments }\end{array}$ \\
\hline 2 & $\begin{array}{l}\text { Worry not to be able to complete the } \\
\text { math assignment. }\end{array}$ & $\begin{array}{l}\text { I am worried not to be able to solve a } \\
\text { math } \\
\text { problem. }\end{array}$ \\
\hline 3 & $\begin{array}{l}\text { Increased tense when the math task } \\
\text { completion time is almost over. }\end{array}$ & $\begin{array}{l}\text { I become anxious when the time to do } \\
\text { math is almost over. }\end{array}$ \\
\hline 4 & $\begin{array}{l}\text { Nervous when completing math as- } \\
\text { signments. }\end{array}$ & I am nervous when facing a math problem. \\
\hline 5 & Pale when solving math problems. & $\begin{array}{l}\text { I become doughy when I am solving a } \\
\text { math problem. }\end{array}$ \\
\hline 6 & $\begin{array}{l}\text { Hand is shaking when I am solving } \\
\text { math problems in front of the class. }\end{array}$ & $\begin{array}{l}\text { Hand is shaking when I am solving math } \\
\text { problems in front of the class. }\end{array}$ \\
\hline 7 & $\begin{array}{l}\text { A cold sweat when going to present to } \\
\text { the class a math assignment. }\end{array}$ & $\begin{array}{l}\text { I am sweating when presenting exercise } \\
\text { during math class. }\end{array}$ \\
\hline 8 & $\begin{array}{l}\text { Knee was shaking when answering } \\
\text { questions of the teacher. }\end{array}$ & $\begin{array}{l}\text { The knee is shaking when I answer to the } \\
\text { questions of the teacher. }\end{array}$ \\
\hline 9 & $\begin{array}{l}\text { Body is stiff due to the tension when I } \\
\text { am learning of mathematics. }\end{array}$ & $\begin{array}{l}\text { The body is tensioned when I am in the } \\
\text { math lesson. }\end{array}$ \\
\hline 10 & $\begin{array}{l}\text { Irregular heart beats when completing } \\
\text { math assignments. }\end{array}$ & $\begin{array}{l}\text { My heart is in my moth when completing } \\
\text { a math problem. }\end{array}$ \\
\hline 11 & $\begin{array}{l}\text { I don't focus when learning mathemat- } \\
\text { ics. }\end{array}$ & $\begin{array}{l}\text { I have difficulties to pay attention to the } \\
\text { teacher while studying mathematics. }\end{array}$ \\
\hline 12 & $\begin{array}{l}\text { Raised their hands to answer a teach- } \\
\text { er's question. }\end{array}$ & $\begin{array}{l}\text { I don't raise hand to answer a teacher's } \\
\text { question. }\end{array}$ \\
\hline
\end{tabular}




\begin{tabular}{cll}
\hline No. & \multicolumn{1}{c}{ Statement Before Validation } & \multicolumn{1}{c}{ Statement After Validation } \\
\hline 13 & $\begin{array}{l}\text { Not going to class when learning of } \\
\text { mathematics }\end{array}$ & $\begin{array}{l}\text { I don't go to class when we have math les- } \\
\text { sons. } \\
\text { My math assignments are overdue. }\end{array}$ \\
14 & $\begin{array}{l}\text { Late collect math assignment. } \\
15\end{array}$ & No matter the math assignment. \\
16 & Avoid math. & I don't mind to do the math assignments. \\
\end{tabular}

The problem of data reduction, data presentation, and conclusion/verification into the image contained a series of activities. Furthermore, the data was analyzed, described and interpreted in the form of words to describe the facts.

Based on the information that has been described previously, each stage in the process is carried out to obtain the validity of the data by examining all the data available from various sources.

\section{Comparing the questionnaire with the existing ones:}

There are similar questions related to feelings in this questionnaire psycholocal symptoms. But the psychological symptoms are lacking in the exisisting questionnaires as well some of the sociological symptoms are lacking. This questionnaire is narrower when we think about feelings but there are four questions related to feelings classes of are there. However they seem to have stronger expresions example:

- The following question "I am afraid to get a wrong answer when completing math assignments" is formulated by Jameson (2013) "When I solve math problems I feel" and by

- The following question "I am worried not to be able to solve a math problem" is formulated by Jameson (2013) "When I think about doing math I feel"

The questions like 5,6,7,8,9 that are related to physiological reactions were not mentioned in other math anxiety questionnaires but might be seen as questions related to feeling.

- The question 6 "Hand is shaking when I am solving math problems in front of the class" While in the other questionnaires they are formulated "If I have to add up numbers on the blackboard in front of the class, I feel" Jameson (2013)

- The questions that have sociological viewpoint like Question 11 "I don't raise hand to answer a teacher's question" are visible in other questionnaires in form of asking feelings "(Jameson (2013).

\section{$4 \quad$ Result math anxiety interviews}

90 pupils were interviewed. 60 answers were possible to be analysed. The teachers evaluated separately their pupils. 
The questionnaire summary gives anxiety level points. The data obtained can be seen in Table 2 below:

Table 2. Results Anxiety Level Math Pupils

\begin{tabular}{lcc}
\hline \multicolumn{1}{c}{ Interval } & Category & Number of Pupils \\
\hline $71.46<x \leq 80$ & Very High & 0 \\
$54.4<x \leq 71.46$ & High & 2 \\
$41.6<x \leq 54.4$ & Medium & 13 \\
$24.53<x \leq 41.6$ & Low & 38 \\
$16<x \leq 24.53$ & Very Low & 7 \\
\hline
\end{tabular}

The Table 2 shows the results of math anxiety level. The result show that math anxiety level is low for 38 pupils, high for 2, medium for 13 , and very low for 7 pupils none of the had very high math anxiety.

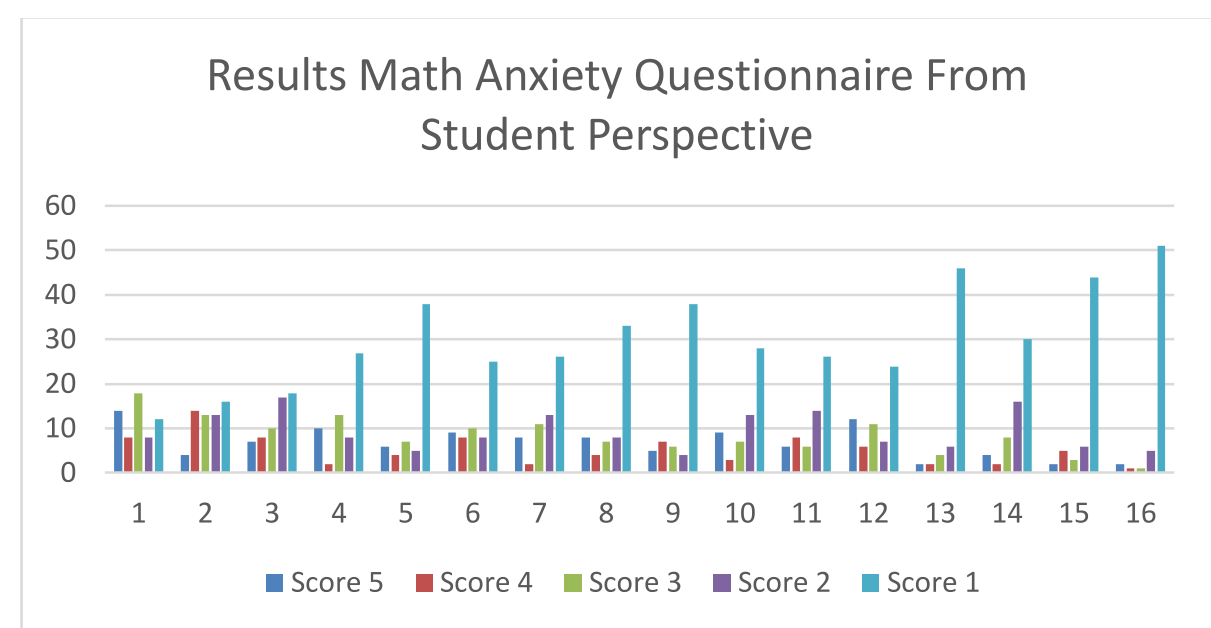

Fig. 1. Graph Results Math Anxiety Questionnaire from the Perspective of Pupils

1. A total of 16 pupils are sometimes afraid of getting a wrong answer when completing math assignments.

2. 17 pupils had not been worried about failing to solve a math problem

3. 20 pupils had not been anxious when the time to do math is almost over.

4. 28 pupils had not been nervous when they faced a math problem.

5. 39 pupils never felt doughy when doing the math exercises.

6. 26 pupils have never experienced hands trembling when they solved math problems in front of the class.
8. 35 pupils have never experienced knee shaking when they answered math teacher questions.

9. 39 pupils never felt increased tension when doing math exercises

10.30 pupils never felt heart in their mouth when solving a math problem.

11.26 pupils were always able to pay attention to the teacher while studying mathematics.

12.24 pupils were always able to pay attention to the subject during math lessons.

13.46 pupils always go to math lessons. 
7. 27 pupils never were sweating during math classes.
14.30 pupils were never returned late their math assignment.

15.45 pupils don't mind to do their math excesses.

16.53 pupils never avoid mathematics.

The math anxiety of elementary school 03 Sajingan Besar is at a low level since the total points of pupils is between 24,5 and 41 . In addition, researchers also gave the questionnaire to the teachers of the pupils who evaluated their pupils' math anxiety. The data of teachers can be seen in the chart below:

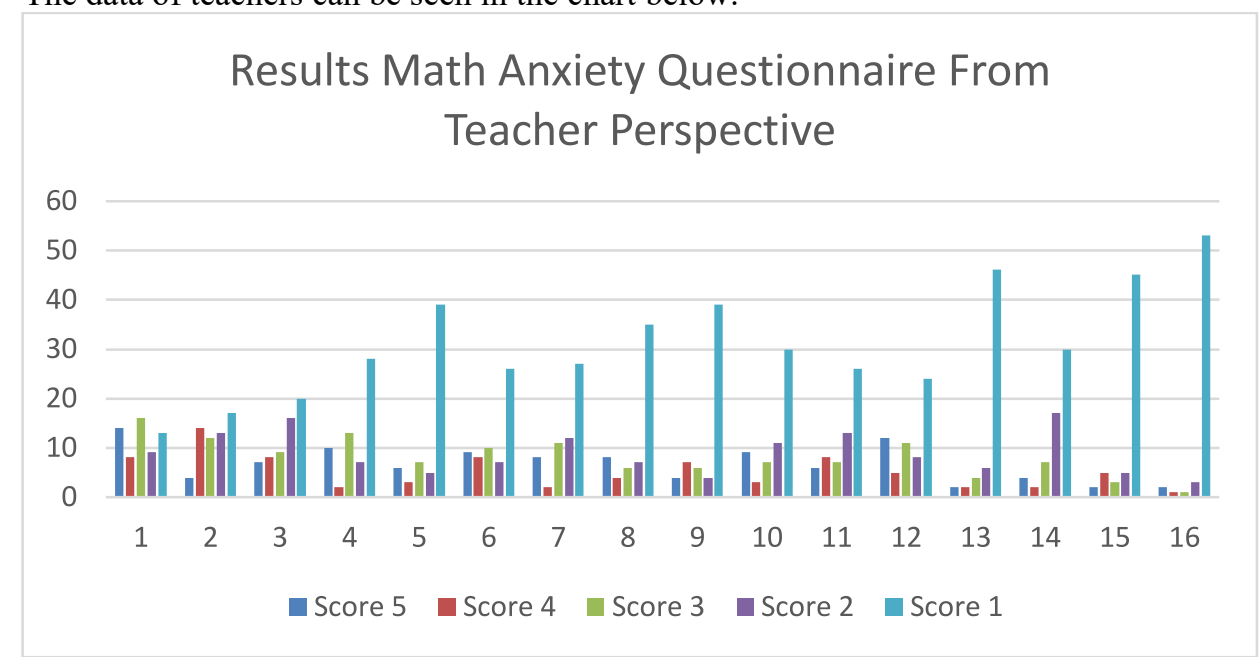

Fig. 2. Graph Results Math Anxiety Questionnaire From Teacher Perspective

1. A total of 16 pupils are sometimes afraid giving wrong answer when they are solving math problem.

2. 17 pupils had not been worried about failing to solve a math problem.

3. 20 pupils had not been anxious when the time to do math is almost over.

4. 28 pupils had not been nervous when they faced a math problem.

5. 39 pupils never felt doughy when they were doing the math.

6. 26 pupils have never experienced hands tremling when solving math problems in front of the class.

7. 27 pupils were never sweating during math class.

8. 35 pupils never experienced knee shaking when they answered questions from the teacher.
9. 39 pupils never felt increased tension when they were doing math exercises 10.30 pupils never felt heart in their mouth when they were solving a math problem. 11.26 pupils were always able to pay attention to the teacher while studying mathematics.

12.24 pupils always raise their hands to answer the question of the teacher.

13.46 pupils always go to math lessons.

14.30 pupils never returned late their math assignment.

15.45 pupils don't mind to do their math exercises.

16.53 pupils never avoid mathematics. 
The previous statements allow us to conclude that pupils anxiety of elementary school 03 Sajingan Besar according to the viewpoint of the teachers are at a low level. We analyzed the responses to the questionnaires in order to find the error score. This error score serves as a benchmark of how valid the used instrument is.

The calculated error is:

$$
\text { Error score }=\frac{28}{60}=0.46
$$

The score of questionnaire data errors is 0.46 , meaning that the math anxiety questionnaire related to the experienced and observed anxiety of elementary school pupils can be declared valid. In conclusion, pupils' math anxiety questionnaire can be used for research related to the math anxiety of pupils.

The math anxiety questionnaire was created in order to have other viewpoints than only feeling based viewpoint in math anxiety evaluation.

\section{$5 \quad$ Discussion and Results}

Results show that the anxiety level of the pupils was mostly low both from pupils and teachers perspective. The developed math anxiety questionnaire results are not possible to be compared with the earlier results. This might mean that however the math anxiety is higher than the anxiety in the previous studies.

The study revealed that math anxiety questions have earlier focused on psychological feelings but the more serious anxiety symptoms like shaking hands or sweating due to physiological anxiety or social fears linked to math anxiety were not possible to be found in the earlier math anxiety questionnaires. The developed math anxiety questionnaire is unique since it studies psychological, physiological and social elements of math anxiety. However, we have to admit that the translated questionnaire might need further editing before it can be used in other countries.

The math anxiety can be really fatal for pupils and students in later education. It is important to find out who need help, and how the teachers support and discuss of the importance of parents support as well as teachers role in minimizing anxiety.

\section{References}

1. Dacey, J.S., \& Fiore, L.B.: Your anxious child: How parents and teachers can relieve anxiety in children, Jossey-Bass Publishers, San Francisco (2000).

2. Chiu, L.-H. \& Henry, L.L.: Development and validation of the Mathematics Anxiety Scale for Children. In Measurement and evaluation in counseling and development (1990).

3. Engle, R. W.: Working memory capacity as executive attention. Current Directions in Psychological Science, 11(1), 19-23. doi:10.1111/1467-8721.00160 (2002).

4. Freedman, E.. Ten Ways to Reduce Math Anxiety. http://www.mathpower.com/reduce.htm.last accessed (2010) 
5. Furner, J.M. \& Berman, B.T.: Review of research: math anxiety: overcoming a major obstacle to the improvement of student math performance. In Childhood education 79.3, 170-174 (2003)

6. Furner, J. M., \& Marinas, C. A. (2012). Connecting geometry, measurement, and algebra using GeoGebra for the elementary grades. In Twenty-fourth Annual International Conference on Technology in Collegiate Mathematics (pp. 63-72).

7. Gierl, M. J., \& Bisanz, J.: Anxieties and attitudes related to mathematics in grades 3 and 6. The Journal of Experimental Education, 63, 139-158. doi:10.1080/00220973. 995.9943818 (1995).

8. Hamzah, U.B \& Squares, M.: Managing Intelligence in Learning, Earth Literacy, Jakarta (2009).

9. Jackson, E.: Mathematics Anxiety in Student Teachers, Practitioner Research in Higher Education University of Cumbria, 2(1), 36-42 (2008).

10. Jameson, M. M.: The Development and Validation of the Children's Anxiety in Math Scale. Journal of Psychoeducational Assessment, 31(4), 391-395. https://doi.org/10.1177/ 0734282912470131 (2013).

11. Ma, Xin, and Jiangming Xu. "The causal ordering of mathematics anxiety and mathematics achievement: a longitudinal panel analysis." Journal of adolescence 27.2 (2004): 165-179.

12. Mohd Nordin, N. A., Md Tahir, H., Kamis, N. H., \& Khairul Azmi, N. N.: Students' perception and relationship between confidence and anxiety in teaching and learning mathematics: A case study in Sekolah Kebangsaan Bukit Kuda, Klang. In Aip conference proceedings (Vol. 1522, No. 1, pp. 396-399). AIP (2013)

13. Mullis, I.V.S., Martin, M.O., Foy, P., Olson, J.F., Preuschoff, C., Erberber, E., Arora, A., \& Galia, J. : TIMSS 2007 International Mathematics Report: Finding krom IEA's Trends in International Mathematics and Science Study at the Fourth Mac Eighth Grades, TIMSS \& PIRLS International Study Center, Boston College (2008).

14. Mullis, I.V.S., Martin, M.O., Foy, P., \& Arora, A.: TIMSS 2011 International Results in Mathematics. TIMSS \& PIRLS International Study Center, Chestnut Hill (2012).

15. Nevid, J.S., Spencer. A.R., \& Greene, B.: Abnormal Psychology, Publisher, Jakarta (2005).

16. Ramirez, G., Gunderson, E. A., Levine, S. C., \& Beilock, S. L. : Math anxiety, working memory, and math achievement in early elementary school. Journal of Cognition and Development, 14(2), 187-202 (2013).

17. Ramirez, G., Gunderson, E. A., Levine, S. C., \& Beilock, S. L.: Math anxiety, working memory, and math achievement in early elementary school. Journal of Cognition and Development, 14(2), 187-202. http://dx.doi.org/10.1080/15248372.2012.664593 (2013).

18. Rossnan, S.: Overcoming Math Anxiety, Mathitudes, 1(1), 1-4 (2006).

19. Schmeichel, B. J., \& Demaree, H. A.:Working memory capacity and spontaneous emotion regulation: High capacity predicts self-enhancement in response to negative feedback. Emotion (2010).

20. Schmeichel, B. J., Volokhov, R. N., \& Demaree, H. a.:Working memory capacity and the self-regulation of emotional expression and experience. Journal of Personality and Social Psychology, 95(6), 1526-1540 (http://doi.org/10.1037/a0013345) (2008).

21. Sukmadinata, N.S.: The foundation of Psychology Education Process, PPB FIP UNY, Yogyakarta (2004).

22. Suinn, R. M., Taylor, S., \& Edwards, R. W.: Suinn mathematics anxiety rating scale for elementary school students (MARS-E): Psychometric and normative data. Educational and Psychological Measurement, 48(4), 979-986 (1988). 
23. Syachrumsyah.: Kebijakan Pemerataan dan Peningkatan Mutu Pendidikan di Wilayah Perbatasan (Equity and Improvement Policy of Education Quality in Border Area, Cendekia: Jurnal Pendidikan dan Pengajaran, 1(1), 25-45 (2017)

24. Willis, J.: Learning to love math: Teaching strategies that change student attitudes and get results. Alexandria, US: ASCD. Retrieved from http://www.ebrary.com (2010). 